\title{
ANALISIS VISUAL GAME ARENA OF VALOR SEBAGAI DASAR PENGEMBANGAN KONSEP VISUAL GAME
}

\author{
Ricky Widyananda Putra M.Sn, Benny Muhdaliha M.Sn \\ Fakultas Ilmu Komunikasi, Universitas Budi Luhur Jakarta \\ rickywidyanandaputra@budiluhur.ac.id,benny.muhdaliha@budiluhur.ac.id
}

\begin{abstract}
In game design, in addition to having a powerful and interesting gameplay concept, creator should pay attention to the visual aspect embodied in the visual design of the game. Visual aspect is so important to attract user to play it, especially in Multiplayer Online Battle Arena (MOBA) genre game. With the support of visual design, users can easily understand and follow the gameplay faster and and surely they can understand the ability of each character with ease. This research tries to study the visual design and characters design of Arena Of Valor game. With visual perception theory and manga matrix theory to gain an understanding of the visual approach and creator considerations in the game visual design. Hopefully this research can be used as the basis reference for further MOBA game development.
\end{abstract}

Keyword: Game, Perception, Manga Matrix, Arena Of Valor, Visual

\begin{abstract}
ABSTRAK
Perancangan sebuah game selain memiliki konsep gameplay yang kuat dan menarik, harus memperhatikan aspek visual yang diwujudkan dalam rancangan visual game tersebut. Aspek visual begitu penting untuk menarik minat user untuk memainkannya terutama digame yang bersifat Multiplayer Online Battle Arena (MOBA). Dengan perancangan visual game yang didukung oleh perancangan karakter yang tepat, user dapat memahami dan mengikuti gameplay lebih cepat serta dapat memahami kemampuan (ability) dari setiap karakter dengan mudah. Penelitian ini berusaha mengkaji visual Arena Of Valor berdasarkan teori persepsi visual dan teori manga matrix untuk mendapatkan pemahaman akan pendekatan visual yang dilakukan creator game tersebut. Dengan ditemukannya pertimbangan-pertimbangan yang diperlukan dalam perancangan visual dari game Arena Of Valor ini diharapkan dapat digunakan sebagai dasar pengembangan visual game selanjutnya.
\end{abstract}

Kata Kunci: Game, Persepsi, Manga Matrix, Arena Of Valor, Visual

\section{PENDAHULUAN}

Games bukanlah fenomena baru

lagi sebagai alat hiburan, bahkan saat ini masyarakat dapat dengan mudah mendapatkan dan mengakses beragam permainan karena banyak game yang sudah terintegrasi secara sistem dengan beragam gadget atau telepon pintar (smartphone). Akibat integrasi yang dilakukan saat ini bermain games telah menjadi kebiasaan dan kebutuhan sebagian masyarakat untuk melepaskan 
diri dari rutinitas sehari-hari sebagai salah satu media hiburan, bahkan lebih jauh lagi sebagai media untuk dapat berinteraksi dan berekspresi.

Game telah dikenal dan terus diminati oleh masyarakat karena menyajikan suatu permainan yang menghibur dan interaktif. Hal ini menjadikan game sebagai media visual yang efektif untuk mendapatkan pengalaman dan informasi dari interaksi yang dilakukan antar user atau pemain game didalamnya sehingga setiap pemain akan mendapatkan pengalaman berinteraksi dalam adu strategi dan kerjasama serta juga pengetahuan yang didapat dari fasilitas informasi yang disediakan oleh game.

Sebuah game harus dikembangkan dengan konsep yang teliti dan cermat terutama pada parameter visualnya agar tujuan dari kreator dapat tercapai. Tampilan visual adalah sensor pertama yang akan diterima oleh indera yang nantinya akan memiliki peran yang sangat besar untuk menjaring user agar memainkan game tersebut. Oleh karena itu dalam proses perancangan dan pengembangan konsep visual game sangat penting untuk mengenal user yang diharapkan nantinya akan memainkan game tersebut.
Mengenal user dilakukan dengan mengetahui bagaimana user memaknai sebuah tampilan visual atau dikenal dengan persepsi visual. Persepsi visual user dapat dibentuk dengan pengembangan konsep tampilan visual yang dibuat oleh desainer game. Jadi, persepsi user akan dibimbing kearah yang diinginkan pembuat game sehingga diharapkan user dengan mudah menangkap pesan yang disampaikan.

Game sebagai media interaktif dimana didalamnya terdapat interaksi antara game yang diwakili tampilan visual dengan user sebagai penggunanya. Dalam interaksi ini, fokus dan ketertarikan user terhadap apa yang diperlihatkan game menjadi elemen penting agar timbul kesan yang baik dan mendorong user untuk terus memainkannya.

Tampilan visual yang menarik dalam sebuah game, meliputi elemen visual; desain karakter, objek, bentuk dan warnanya, hingga animasi yang sesuai dengan prinsip-prinsip desain dan seni rupa. Multiplayer Online Battle Arena (MOBA) yang dapat diartikan sebagai pertempuran dalam sebuah arena yang dilakukan oleh beberapa pemain secara online, sebuah genre game MOBA lahir dan berkembang 
seiring perkembangan teknologi jaringan komputer (internet).

Berawal dari tahun 1998 setelah seorang pemain dengan inisial Aeon64 merancang custom map dalam game StarCraft (sebuah game realtime strategy yang dikeluarkan oleh Blizard's), dalam custom map diseting setiap pemain hanya dapat mengendalikan satu hero saja, dirancang tiga jalur yang menghubungkan base dari dua tim yang bertanding dengan tujuan untuk menghancurkan base lawan. Setelah itu game MOBA terus berkembang dan banyak dimainkan melalui personal computer $(P C)$ yang terkoneksi baik secara online ataupun jaringan offline yang terdiri dari beberapa $P C$, tidak berhenti disitu saja, seiring dengan perkembangan smartphone dimana saat ini kemampuan teknologinya sudah menyamai bahkan melebihi kecanggihan $P C$, game MOBA pun mulai dirilis untuk versi smartphonenya.

Game Arena Of Valor (AOV) merupakan salah satu game MOBA yang dapat dimainkan lewat perangkat smartphone, sebuah game yang cukup fenomenal tingkat aksesnya dan jumlah pemain yang memainkannnya, terutama di indonesia. Dalam game ini ditampilkan beragam karakter dari berbagai mitologi, seperti Wukong (Warior), Chrest (Tank) dan Krixi (Mage).

Perancangan visual game yang didukung oleh perancangan karakter yang tepat akan membuat user dapat dengan mudah mengidentifikasi setiap elemen visual yang ada, sehingga user dapat mengikuti gameplay dan memahami kemampuan (ability) dari setiap karakter dengan mudah, hal ini tercermin dalam visual game arena of valor. Sampai saat ini aplikasi game arena of valor terus diunduh banyak user melalui playstore dan terus meningkat. Berdasarkan kenyataan tersebut maka menurut peneliti game ini perlu untuk diteliti dan dipelajari agar dapat menjadi referensi dan pertimbangan dalam pengembangan visual dari game MOBA yang akan datang.

\section{Persepsi Visual}

Menurut Davidof dalam Walgito (2004), persepsi merupakan proses yang digunakan oleh seseorang individu untuk memilih, mengorganisasi dan menginterpretasikan masukan-masukan informasi guna menciptakan gambaran dunia yang memiliki arti. Persepsi tidak hanya bergantung pada rangsangan fisik tetapi juga pada rangsangan yang 
berhubungan dengan lingkungan sekitar dan keadaan individu bersangkutan.

Mata sebagai indera penglihatan (visual) erat kaitannya dengan pembentukan persepsi manusia. Dengan hanya melihat sesuatu hal maka otak akan merespon dan menterjemahkan dalam bentuk interpretasi. Reaksi otak terhadap apa yang dilihatnya sangat beragam, tergantung pula pada pengalaman hidupnya. Otak mempersepsikan objek visual dengan cara mengorganisasikan komponenkomponen sensasi yang memiliki hubungan, pola, ataupun kemiripan menjadi kesatuan(holistik). Hal seperti itulah yang disebut persepsi visual. Sarwono (2012) mengemukakan bahwa persepsi visual memiliki beberapa prinsip, yaitu:

a. Wujud dan latar (figure and ground)

Objek yang kita amati di sekitar kita selalu muncul sebagai wujud (figure) sedangkan hal-hal lainya namun tidak menjadi fokus yang diamati disebut latar (ground). Sebagai contoh apabila kita melihat meja di dalam ruangan, maka meja itu adalah suatu wujud, sedangkan hal lain seperti lantai, dinding, jendela dan lain sebagainya merupakan suatu latar. Ada kalanya perbedaan antara wujud dan latar tidak begitu jelas, sehingga kita harus memilih mana yang dianggap wujud dan sebaliknya mana yang dianggap sebagai latar.

b. Pola pengelompokan (teori Gestalt) Secara sadar atau tidak sadar, kerap kali kita mengkelompokkan beberapa hal dalam persepsi kita. Pengelompokan tersebut menentukan bagaimana kita mengamati suatu hal. Dalam ilmu psikologi kecenderungan manusia untuk mengelompokkan persepi dinamakan hukum Gesalt. Termasuk di dalamnya adalah hukum kesamaan, hukum kedekatan dan hukum

c. Ketetapan (constancy atau invariance)

Teori Gestalt juga mengemukakan bahwa dari proses belajar manusia cenderung mempersepsikan segala sesuatu sebagai sesuatu yang tidak berubah, walaupun indera kita menangkap adanya perubahan. Misalnya kita bertemu bernama seseorang bernama Peter, maka kita akan mengenal Peter walaupun dia menggunakan pakaian dan gaya yang berbeda setiap harinya. Dalam persepsi ada tiga ketetapan dasar yang dikemukakan dalam Psikologi Gesalt, yaitu Ketetapan Warna, Ketetapan Bentuk, dan Ketetapan Ukuran. 


\section{Manga Matrix}

Sebuah metode yang dikembangkan oleh Hiroyoshi Tsukamoto untuk merancang karakter baru dengan metode matematik. Sistem pembuatan karakter diurai dari elemen - elemen pembangunnya yang kemudian disederhanakan kedalam sebuah diagram yang nantinya dijadikan panduan dalam proses penciptaan sebuah karakter.

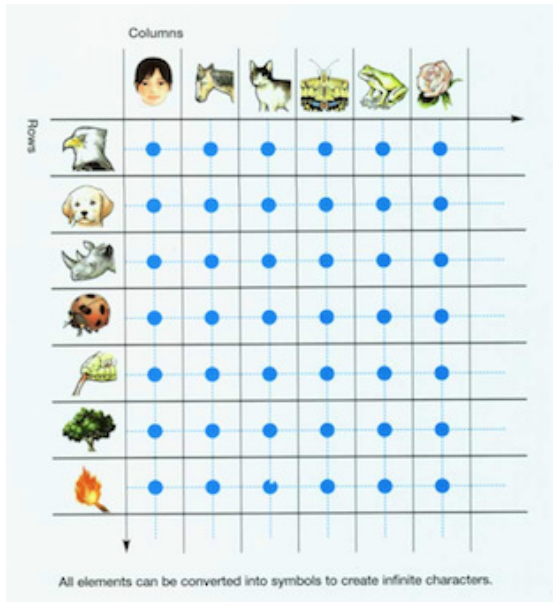

Gambar 1. Manga matrix Hiroyoshi Tsukamoto (2006)

Metode perancangan karakter dalam teori matrix system terdapat tiga variabel yang dijadikan landasan penciptaan sebuah karakter, yaitu :

\section{a. Form Matrix (Matrik bentuk)}

Perancangan struktur dan bentuk tubuh yang mengacu pada elemen elemen pembentuk tubuh karakter yang kemudian dikombinasikan agar menghasilkan tipe karakter yang baru.

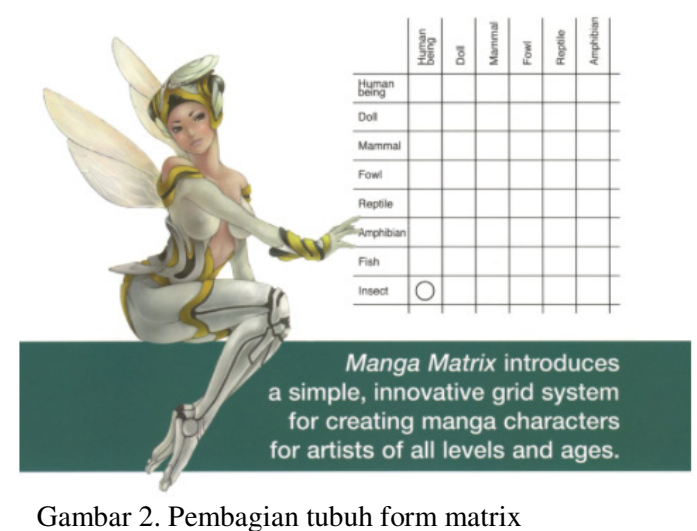

Kemudian untuk mengembangkan tipe tubuh bisa menggunakan berbagai parameter: fixed form, nonfixed form, collective form, mechanical form, cracked form, increase/decrease, length span, growth, combination.

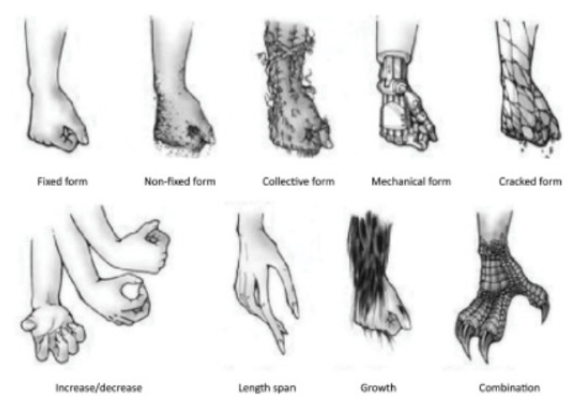

Gambar 3. Parameter form matrix Hiroyoshi

$$
\text { Tsukamoto }
$$

\section{b. Costume Matrix (limitless costumes)}

Setelah karakter tubuh terbentuk dapat dipikirkan seperti manusia yang baru lahir dan bisa memakai kostum apapun. Kostum digunakan 
sebagai pelengkap dalam

memperkuat identitas karakter baru.

Dengan pertimbangan parameter list

dalam matrix system. Memilih salah

satu list parameter dalam merancang

kostum dari atas kepala sampai

ujung kaki yang sesuai dengan

karakter baru.

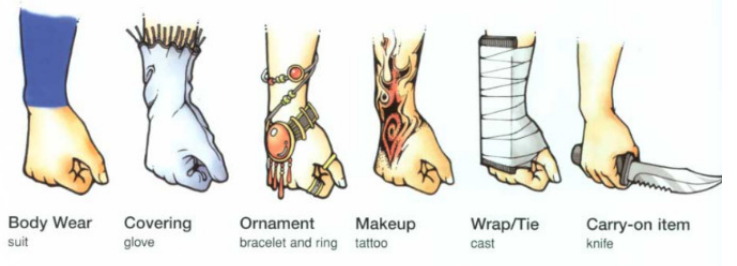

Gambar 4. Parameter costume matrix Hiroyoshi

Tsukamoto

Klasifikasi parameter kostum

meliputi: Body wear, covering/footwear, ornament, makeup, wrap/tie, carry-on item dan klasifikasi material kostum: heaven, earth, water/ fire, inorganic matter, image.

\section{c.Personality Matrix (limitless personal- ities)}

Sejak karakter dibentuk dia belum memiliki personality tetap. Semacam kertas kosong dan perlu menentukan personalitynya secara bebas. Ada enam parameter yang digunakan untuk mengilustrasikan personality karakter yaitu: behavor, Status, profession, position, bioligical environment, special attributes, weaknes, dan desire.

\section{METODE PENELITIAN}

Dengan
pendekatan deskriptif
Penelitian ini dilakukan untitatif.
memberikan gambaran yang lebih
detail mengenai elemen-elemen visual
yang mempengaruhi penciptaan
tampilan visual dan karakter-karakter
yang terdapat di dalam game Arena of
Valor. Secara kualitatif, penelitian ini
bermaksud untuk memahami
pendekatan yang dilakukan dalam
perancangan tampilan dan karakter -
karakter yang terdapat didalamnya.

\section{HASIL DAN PEMBAHASAN}

Istilah Valor memiliki arti keberanian seorang pahlawan dalam menghadapi bahaya, khususnya dalam pertarungan. Pengertian ini mengandung nilai yang sama dalam game Arena Of Valor, bahwa untuk meraih kemenangan, User (Pemain game) membutuhkan kombinasi yang baik antara skill, kerjasama tim dan tentunya keberanian untuk bertindak. Lantas daya tarik apa sehingga game Arena Of Valor (AOV) menjadi game yang populer saat ini. Karena game ini menampilkan kualitas grafis terbaik dari game sejenis, kualitas grafis dan 
tampilan gambar menjadi hal pertama yang dilihat para User (Pemain Game).

Sehingga para User akan tertarik untuk memainkan game tersebut.

Dari sistem game, biasanya ketika bermain game sejenis, para User akan memilih Hero dengan skill ( kemampuan ) yang tinggi. Sehingga tak jarang para User akan mengeluarkan uang untuk membeli skin yang berguna untuk menambah skill dan untuk membuat tampilan Hero lebih menarik. Akan tetapi, hal ini tidak berlaku ketika kamu bermain game AOV. Dalam game ini skin hanya berguna untuk membuat tampilan Hero semakin menarik. Sehingga untuk menambah skill Hero tergantung pada kemampuan para pemainnya. Tak hanya itu, ketika bermain dan ada pemain yang tidak sesuai atau memiliki sikap yang tak baik, pemain lainnya bisa melaporkannya secara langsung. Sehingga pemain tersebut mendapatkan peringatan dari sistem dan terkena pengurangan poin.

Pengunduh game ini pada playstore cukuplah banyak, ini bisa dilihat dari angka penguduh mencapai 284.730 User. Hal ini menandakan bahwa game Arena of Valor (AOV) menjadi game yang populer saat ini, untuk kategori game Arena.

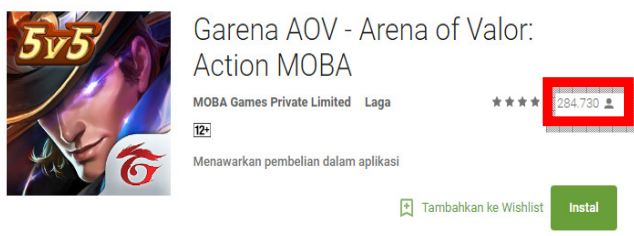

Gambar 5. Data pengunduh game Arena Of Valor pada playstore (Sumber :

https://play.google.com/store/apps/details?id=c om.garena.game.kgid)

Kemudian game Arena of

Valor dalam perkembangannya muncul dalam 3D game. Hal ini melengkapi kajian analisis pengembangan konsep visual 3D game dengan metode komparasi. Itulah mengapa game Arena Of Valor sangat layak untuk menjadi acuan pengembangan konsep visual game.

\section{Analisis Model Pengembangan}

\section{Visual Game}

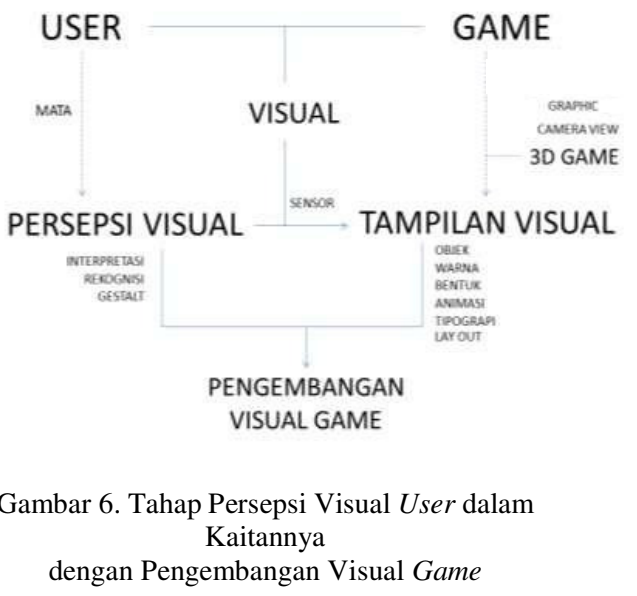

Persepsi visual mengenai tampilan visual game yang meliputi objek, karakter, bentuk dan warna, animasi, dan desain layout, akan 
diinterpretasi oleh user melalui otaknya sebagai sebuah satu makna yang saling berkaitan yang memiliki satu kesatuan desain sebagai sebuah game. Tampilan visual yang baik akan menarik user untuk memberikan respon dengan mulai memainkan game tersebut. Kemudian saat user memainkan game, dia akan mulai menganalisis setiap elemen visual game untuk mengenali lingkungan game yang ditampilkan oleh sipembuat game. Maka disinilah tugas pembuat game untuk dapat membuat konsep visual game dengan elemen visual yang mudah dipahami oleh user.

Kecenderungan user melihat setiap elemen visual sebagai sebuah kesatuan visual dalam wujud sebuah game memberikan perhatian lebih pada pengembangan konsep layout game, yaitu pengorganisasian keseluruhan elemen-elemen visual game yang ditata letaknya sedemikian rupa, agar user mampu menginterpretasikan desain tersebut sebagai sebuah desain yang enak dilihat dan memacu untuk berinteraksi dengannya. Sehingga user yang telah tertarik dengan tampilan visual game dan mulai memainkannya akan berupaya masuk lebih jauh, memainkan game hingga selesai. Dan akhirnya user akan merasa terbawa oleh permainan, merasa terhibur dan secara tak langsung menerima pesan yang tersirat dalam game tersebut.

\section{Analisis Game Arena Of Valor \\ Dalam Kajian Persepsi Visual}

User

Game Arena Of Valor hadir dalam bentuk $3 D$ game, hal ini sebagai bukti eksistensi dalam menghadirkan game yang sesuai dengan perkembangan teknologi visual saat ini.

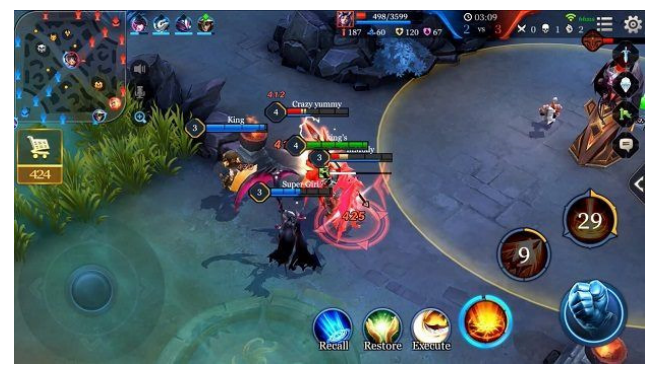

Gambar 7. Tampilan game Arena Of Valor

Genre game ini dapat dianalisis tampilan visualnya dengan metode komparasi sebagai dasar pengembangan game dan hasilnya adalah sebagai berikut:

Tabel 1.

Karakteristik Umum Persepsi User Tentang Objek Karakter Lingkungan

Pada Tampilan Visual Game Arena Of Valor

\begin{tabular}{|c|l|}
\hline Parameter & $\begin{array}{l}\text { Game Arena } \\
\text { Of Valor } \\
\text { (AOV) }\end{array}$ \\
\hline $\begin{array}{l}\text { Objek : Karakter } \\
\text { Lingkungan }\end{array}$ & $\begin{array}{l}\text { Cenderung User } \\
\text { melihat sebagai } \\
\text { unsur visual } \\
\text { bergerak secara } \\
\text { dinamis dan nyata }\end{array}$ \\
\hline & $\begin{array}{l}\text { Kekuatan } \\
\text { modelling objek }\end{array}$ \\
\hline & $\begin{array}{l}\text { Detail karakter } \\
\text { lingkungan dan } \\
\text { gerak animasi, } \\
\text { bentuk } \\
\text { proposional }\end{array}$ \\
\hline
\end{tabular}


Pemberian warna mempertimbangk an tingkat point of interest

Pandangan user ketika melihat tampilan visual game berupa objek yaitu karakter dan aset environment/lingkungan mereka menekankan pada tampilan objek yang mudah dikenali mana karakter, mana lingkungannya. Sehingga konsep nirmana sangat menentukan tercapainya pesan tersebut yaitu tentang bagaimana kejelasan sebuah objek, detail, warna, kesatuannya dan bentuknya.

Tabel 2.

Karakteristik Umum Persepsi User Tentang View Camera

Pada Tampilan Visual Game Arena Of Valor

\begin{tabular}{|c|c|}
\hline Parameter & $\begin{array}{c}\text { Game Arena } \\
\text { Of Valor } \\
\text { (AOV) }\end{array}$ \\
\hline \multirow[t]{4}{*}{$\begin{array}{l}\text { View Kamera (Sudut } \\
\text { Pandang) }\end{array}$} & $\begin{array}{l}\text { Daya Eksplorasi } \\
\text { User tinggi }\end{array}$ \\
\hline & $\begin{array}{l}\text { Identifikasi } \\
\text { visual User } \\
\text { dengan } \\
\text { Eksplorasi }\end{array}$ \\
\hline & $\begin{array}{l}\text { Cenderung fokus } \\
\text { terbagi pada } \\
\text { beberapa objek } \\
\text { visual }\end{array}$ \\
\hline & $\begin{array}{l}\text { Interpretasi lebih } \\
\text { lama }\end{array}$ \\
\hline
\end{tabular}

View disini adalah tampilan yang diperlihatkan oleh kamera atau tampilan layar dalam game. Pada tampilan game Arena Of Valor menggunakan 3D yang cenderung dinamis, penuh dengan kedalaman dan terlihat realistis. User memandang view sebagai daya eksplorasi persepsi mereka, tingkat fokus penglihatan mereka, dan tingkatan kecepatan mereka menginterpretasikan objekobjek visual. Pengenalan objek yang lebih cepat diinterpretasikan memungkinkan pesan lebih mudah dipahami oleh user.

Tabel 3.

Karakteristik Umum Persepsi User Tentang Komposisi

Pada Tampilan Visual Game Arena Of Valor

\begin{tabular}{|c|c|}
\hline Parameter & $\begin{array}{c}\text { Game } \\
\text { Arena Of } \\
\text { Valor } \\
\text { (AOV) }\end{array}$ \\
\hline \multirow[t]{3}{*}{$\begin{array}{l}\text { Komposisi } \\
8 \% \\
0\end{array}$} & $\begin{array}{l}\text { Fokus utama } \\
\text { game yaitu } \\
\text { karakter, } \\
\text { sehingga elemen } \\
\text { visual game } \\
\text { lebih mudah } \\
\text { diinterprestasika } \\
\text { n } \\
\end{array}$ \\
\hline & $\begin{array}{l}\text { Setiap elemen } \\
\text { game saling } \\
\text { mendukung } \\
\text { dalam } \\
\text { memperlihatkan } \\
\text { pusat perhatian } \\
\text { pada karakter }\end{array}$ \\
\hline & $\begin{array}{l}\text { Pencahayaan } \\
\text { yang baik, } \\
\text { memudahkan } \\
\text { identifikasi unsur } \\
\text { visual }\end{array}$ \\
\hline
\end{tabular}

Komposisi dalam peletakan objek-objek visual serta teknik pengambilan kamera mempengaruhi tingkat kemudahan user menginterpretasikan objek. Objek yang dinamis seperti karakter akan dikenali oleh user pertama kali, sehingga sangat penting pengaturan komposisi yang 
mengedepankan objek sebagai pusat perhatian.

Tabel 4.

Karakteristik Umum Persepsi User Tentang Desain Layout

Pada Tampilan Visual Game Arena Of Valor

\begin{tabular}{|l|l|}
\hline \multirow{2}{*}{ Parameter } & $\begin{array}{l}\text { Game Arena } \\
\text { Of Valor } \\
\text { (AOV) }\end{array}$ \\
\hline Layout & $\begin{array}{l}\text { Setiap unsur } \\
\text { visual game } \\
\text { sebagai satu } \\
\text { bagian yang } \\
\text { memiliki }\end{array}$ \\
interaksi
\end{tabular}

Desain tata letak memberikan

informasi secara keseluruhan pada layar permainan. Darley (1986) melihat kecenderungan pengorganisasian tata letak secara keseluruhan ada pada prinsip-prinsip gestalt tentang pengelompokan (gestalt priciples of grouping) yang berpijak pada kecenderungan manusia untuk mengorganisasi stimuli yang terpisah menjadi pengelompokan yang berdasar pada proximity (kedekatan), similarity (kemiripan), closure (ketertutupan), continuity (kesinambungan), dan symmetry (simetris). Pada tampilan visual game prinsip kesatuan, kesamaan, jarak, dan alur sangat berpengaruh besar di sini. User memandang desain layout yang mampu menyatukan beberapa kriteria bentuk objek yang berbeda, memiliki kesamaan, terdapat jarak dan alur sebagai desain yang lebih mudah dipahami oleh user. Tidak membingungkan, dan pesan akan sampai pada user.

Selain memberikan gambaran bagaimana persepsi user dalam melihat pola-pola hubungan dalam sebuah tampilan visual game, penelitian ini juga menemukan pengaruh persepsi visual game terhadap user yaitu:

1. User memiliki fokus yang lebih terhadap apa yang terjadi di sekelilingnya

2. Peningkatan dalam visual skill.

3. Meningkatkan kemampuan otak kanan untuk memecahkan masalah yang membutuhkan pengenalan pola, mendeteksi 
kecenderungan-kecenderungan, membuat hubungan-hubungan, dan mengetahui keseluruhan hal.

\section{Analisis Karakter Game Arena Of}

\section{Valor Dalam Kajian Manga Matrix}

Metode analisis yang digunakan

adalah Matrix System, suatu metode yang menekankan pada penerapan suatu kombinasi gagasan terhadap bentuk, wujud, maupun komposisi dimana elemen-elemen tersebut kemudian diolah sedemikian rupa, sehingga menjadi rumusan dasar dari gagasan penciptaan karakter. Untuk desain hero dari game arena of valor yang dianalisa, diwakilkan oleh tiga hero yaitu :

\section{Hero Wukong}

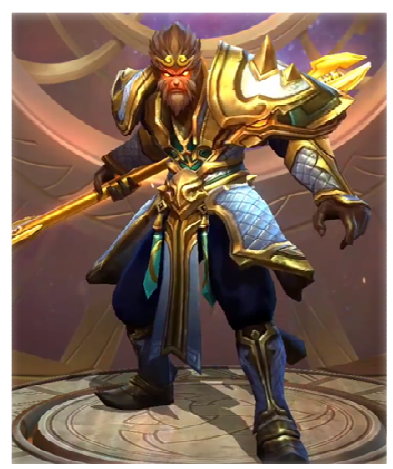

Gambar 8. Hero Wukong

Wukong, Raja Para Monyet, mendatangkan malapetaka ke surga 500 tahun lalu, ketika dia seorang diri mengalahkan 100 ribu prajurit langit. Meskipun begitu, dia tidak dapat kabur dari kekuatan Buddha dan kemudian disegel dibawah gunung lima jari oleh sang Buddha.

\section{Matrix Bentuk (Form Matrix)}

Kemudian

untuk mengembangkan tipe tubuh Karakter Wukong ini menggunakan dua jenis parameter : combination dan collective form. Dengan mengkombinasikan figur manusia dan hewan mamalia (Monyet) dan menkolaborasikan kemampuan bergerak (mobility) dari manusia dan monyet.

Tabel 5.

Matrix bentuk Wukong berdasarkan manga matrix

\begin{tabular}{|c|c|c|c|c|c|c|}
\hline & 駕 & $\overline{\bar{\circ}}$ & 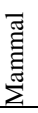 & 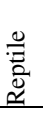 & 葶 & $\frac{5}{5}$ \\
\hline $\begin{array}{l}\text { Human } \\
\text { being }\end{array}$ & & & V & & & \\
\hline Doll & & & & & & \\
\hline Mammal & & & & & & \\
\hline Reptile & & & & & & \\
\hline $\begin{array}{l}\text { Amphibi } \\
\text { an }\end{array}$ & & & & & & \\
\hline Fish & & & & & & \\
\hline Insect & & & & & & \\
\hline
\end{tabular}




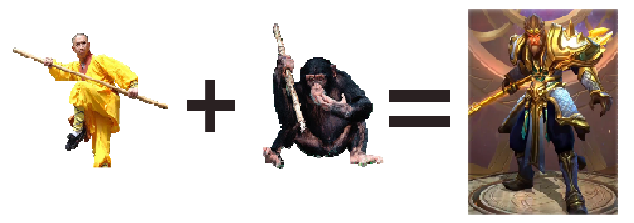

Gambar 9. Skema kombinasi bentuk Hero

Wukong

\section{Costume Matrix}

Kostum digunakan sebagai pelengkap dalam memperkuat identitas karakter. Dengan pertimbangan parameter list dalam matrix system. Klasifikasi parameter kostum dari karakter Wukong meliputi: Body wear, covering/footwear: berupa baju pelindung (baju zirah) lengkap yang memberikan kesan seorang ksatria petarung dan juga menegaskan kemampuan hero ini dalam menahan atau menerima serangan lawan, lengkap dengan cover sarung tangan dan sepatu, carry-on item : berupa sebuah tongkat yang mengindikasikan kemampuan dan keahlian wukong dalam bertarung menggunakannya. Klasifikasi material kostum: inorganic matter.

\section{Personality Matrix (Sifat Lahir)}

Tabel 6.

Matrix sifat Wukong berdasarkan manga matrix

\begin{tabular}{|l|l|}
\hline & $\begin{array}{l}\text { Behavor : } \\
\text { Tidak bisa diam, lincah }\end{array}$ \\
\cline { 2 - 3 } & $\begin{array}{l}\text { Desire : } \\
\text { menggunakan kemampuan } \\
\text { untuk menguasai arena of } \\
\text { valor }\end{array}$ \\
\cline { 2 - 2 } & $\begin{array}{l}\text { Biological environment : } \\
\text { Daerah pegunungan }\end{array}$ \\
\hline
\end{tabular}

\begin{tabular}{|l|l|}
\hline & $\begin{array}{l}\text { Special Atribut : } \\
\text { mampu menyembunyikan } \\
\text { diri, melompat seketika ke } \\
\text { lawan dengan menimbulkan } \\
\text { damage yang besar pada } \\
\text { lawan serta mahir dalam } \\
\text { menggunakan tongkat }\end{array}$ \\
\cline { 2 - 3 } & $\begin{array}{l}\text { Weakness : } \\
\text { tingkat kesulitan } \\
\text { mengendalikan hero ini } \\
\text { cukup tinggi }\end{array}$ \\
\cline { 2 - 2 } & $\begin{array}{l}\text { Status, Profession, position } \\
: \\
\text { warior }\end{array}$ \\
\hline
\end{tabular}

2. Hero Cresht

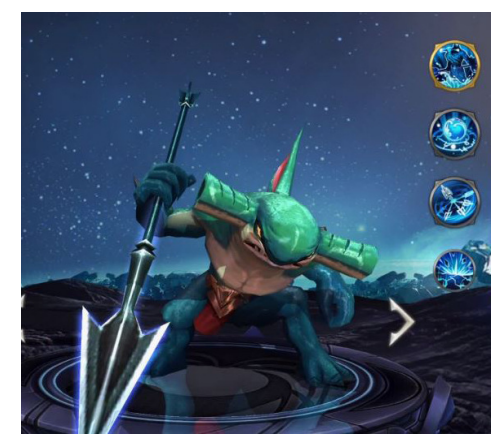

Gambar 10. Hero Chrest

Cresht sang mermidon, berasal dari lautan mendidih yang dinamakan bukan karena suhunya akan tetapi karna adanya pertempuran tanpa akhir disana, dan chrest berada di puncak rantai makanan. Cresh suka disenandungkan para pelaut sebagai kegelapan yang muncul dari laut terdalam, dengan membawa trisula yang sangat mengerikan, cresht datang tidak membawa apa apa kecuali kematian.

\section{Form Matrix}

Kemudian untuk mengembangkan tipe tubuh Karakter 
Chrest ini menggunakan dua jenis parameter : combination dan collective form. Dengan mengkombinasikan figur manusia dan hewan laut (Ikan Hiu) dan dapat melakukan metamorf menjadi besar dan menkolaborasikan kemampuan bergerak (mobility) dari manusia.

Tabel 7.

Matrix bentuk Chrest berdasarkan manga matrix

\begin{tabular}{|c|c|c|c|c|c|c|c|}
\hline & 趌 & $\overline{\bar{\circ}}$ & 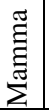 & 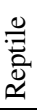 & 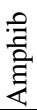 & 垔 & 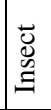 \\
\hline $\begin{array}{c}\text { Human } \\
\text { being }\end{array}$ & & & & & & $\mathrm{V}$ & \\
\hline Doll & & & & & & & \\
\hline Mamma & & & & & & & \\
\hline Reptile & & & & & & & \\
\hline $\begin{array}{c}\text { Amphib } \\
\text { an }\end{array}$ & & & & & & & \\
\hline Fish & & & & & & & \\
\hline Insect & & & & & & & \\
\hline
\end{tabular}

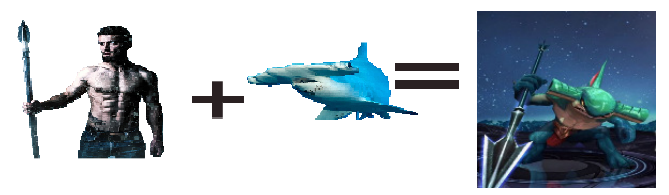

Gambar 11. Skema kombinasi bentuk Hero Chrest

\section{Matrik Kostum (Costume Matrix)}

Kostum digunakan sebagai pelengkap dalam memperkuat identitas karakter. Dengan pertimbangan parameter list dalam matrix system.
Klasifikasi parameter kostum dari karakter Chrest meliputi: Body wear: berupa celana pendek, carry-on item : berupa sebuah tobak yang mengindikasikan kemampuan dan keahlian cherst dalam bertarung menggunakannya..

\section{Personality Matrix (Sifat Lahir)}

Tabel 8.

Matrix sifat Chrest berdasarkan manga matrix

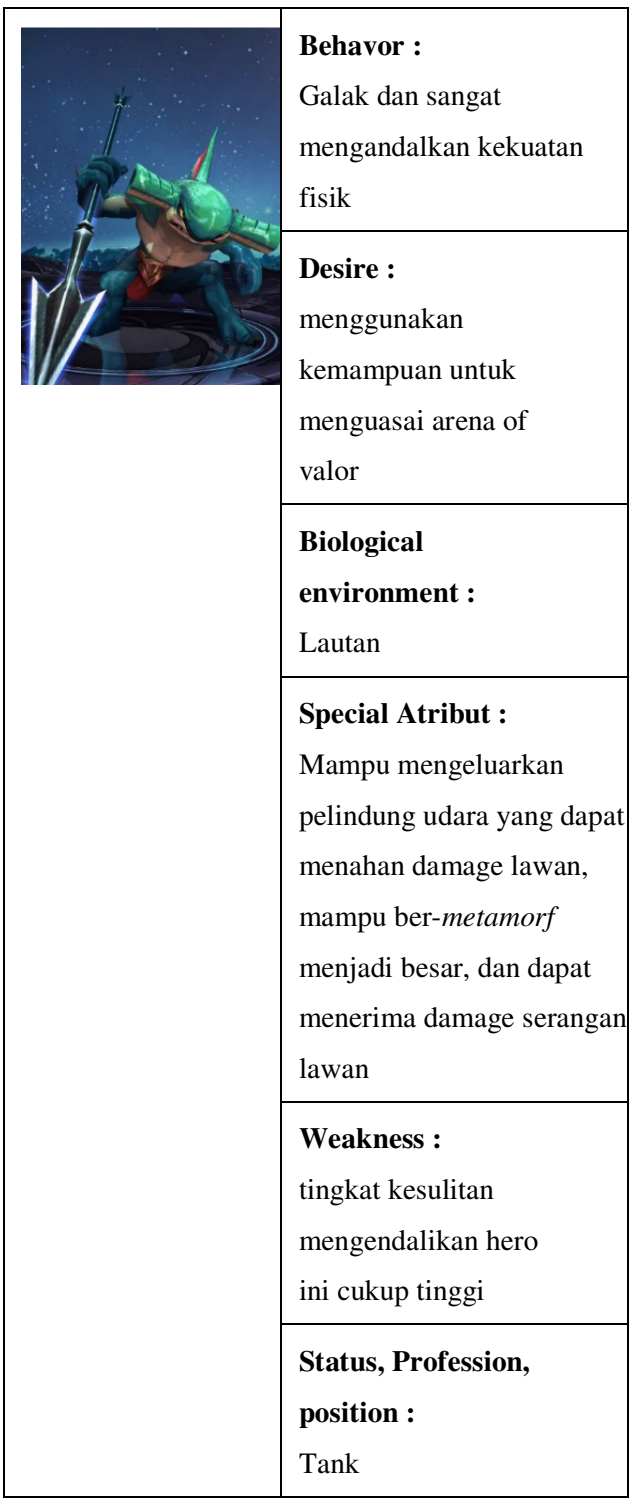




\section{Hero Krixi}

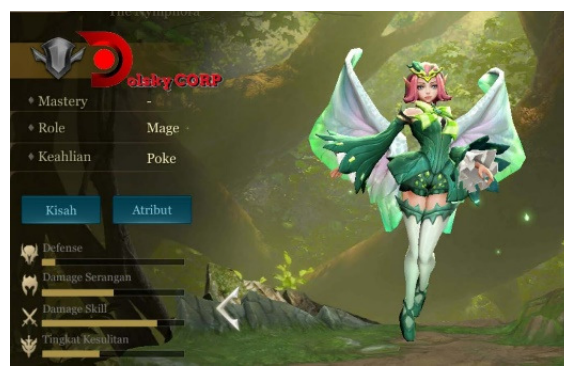

Gambar 12. Hero Krixi

Krixi, sang peri hutan, seperti peri hutan lainnya krixi dapat ditemukan sedang berdansa diantara bunga dan bermain dengan hewan hewan hutan lainnya, namun ketika datang bahaya sisi jahat krixi akan muncul, dengan gigi taring dan cakar yang tajam, krixi akan membasmi monster yang merusak hutan.

\section{Form Matrix}

Kemudian

untuk mengembangkan tipe tubuh Karakter Krixi ini menggunakan dua jenis parameter : combination dan collective form. Dengan mengkombinasikan figur manusia dan hewan serangga (kupu-kupu) dan menkolaborasikan kemampuan bergerak (mobility) dari manusia dan kupu-kupu.
Tabel 9.

Matrix bentuk krixi berdasarkan manga matrix
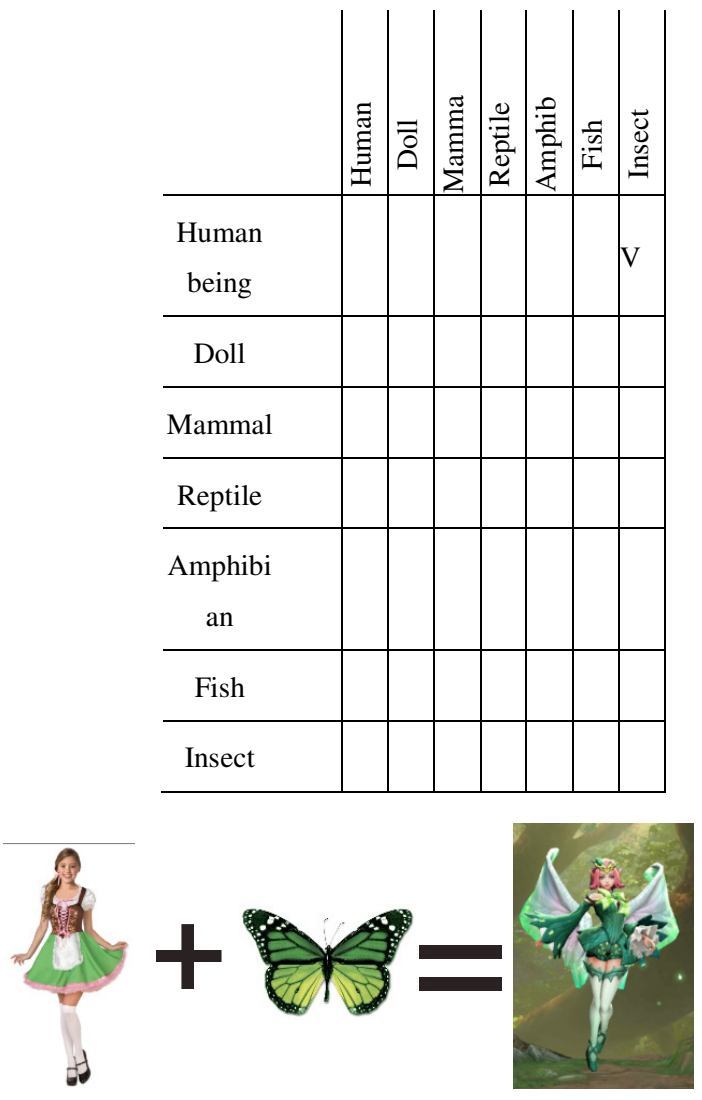

Gambar 13. Skema kombinasi bentuk Hero Krixi

\section{Matrik Kostum (Costume Matrix)}

Kostum digunakan sebagai pelengkap dalam memperkuat identitas karakter. Dengan pertimbangan parameter list dalam matrix system. Klasifikasi parameter kostum dari karakter Wukong meliputi: Body wear, covering/footwear: berupa dress ringkas yang terbuat dari dedaunan hutan, dengan nuansa hijau layaknya baju peri hutan umumnya, dengan tujuan untuk memfasilitasi kemampuan bergerak krixi Klasifikasi material 
kostum: organic matter.

\section{Personality Matrix (Sifat Lahir)}

Tabel 10.

Matrix sifat Krixi berdasarkan manga matrix

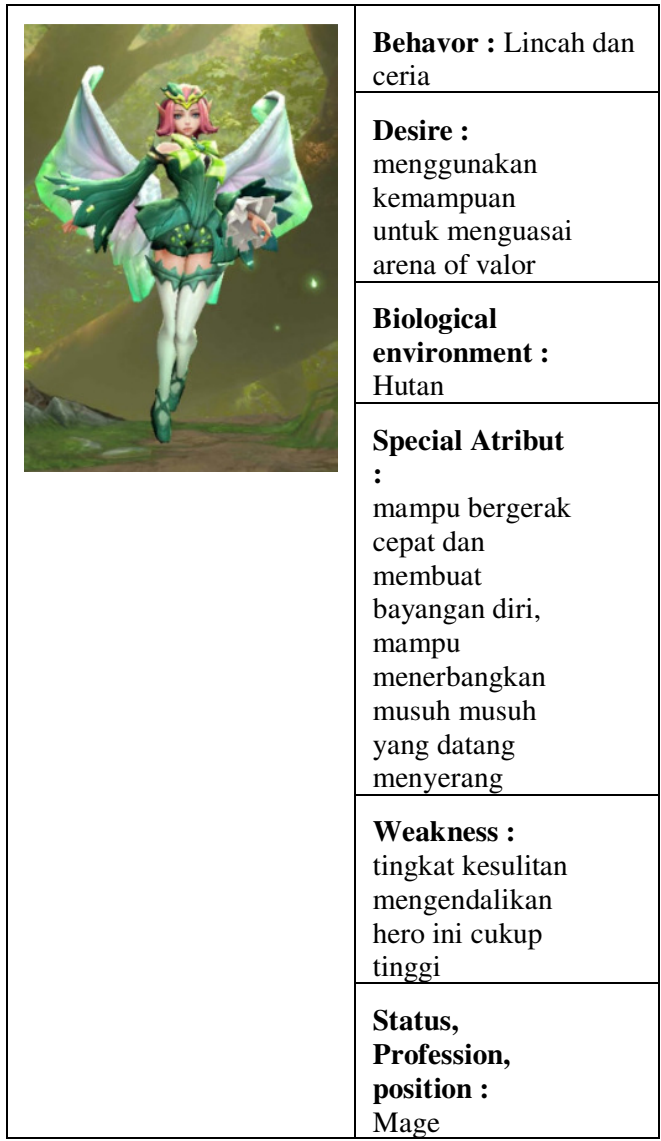

\section{SIMPULAN}

Kualitas grafis dan tampilan gambar menjadi hal pertama yang dilihat para user (pemain game), dengan kualitas visual yang baik akan membuat user tertarik untuk memainkan game tersebut. Sehingga sebuah game harus dikembangkan dengan konsep yang teliti dan cermat terutama pada parameter visualnya agar tujuan dari kreator dapat tercapai. Tampilan visual adalah sensor pertama yang akan diterima oleh indera yang nantinya akan memiliki peran yang sangat besar untuk menjaring user agar memainkan game.

Oleh karena itu dalam proses perancangan dan pengembangan konsep visual game sangat penting untuk mengenal user yang diharapkan nantinya akan memainkan game tersebut. Mengenal user dilakukan dengan mengetahui bagaimana user memaknai sebuah tampilan visual atau dikenal dengan persepsi visual. Persepsi visual user dapat dibentuk dengan pengembangan konsep tampilan visual yang dibuat oleh desainer game.

\section{DAFTAR PUSTAKA}

Aprilia, Shieny dan Widhiyasa, Arief. Membuat Game dengan XNA Game Studio. Bandung: Agate.

Mulyana, Deddy. 2005. Ilmu Komunikasi Sebuah Pengantar. Bandung: PT Remaja Rosdakarya.

Lasswell, Harold D. 1972. The structure and function of communication in society dalam Wilbur Schramm, ed. Mass communication. Chicago: University of Illinois Press.

Darley, John M. 1986. Psychology, 3rd edition. New Jersey: PrenticeHall. 
Sarwono, Sarlito W. 2012. Pengantar Psikologi Umum. Jakarta: Rajawali Pers

Walgito, Bimo. 2004. Pengantar Psikologi Umum. Yogyakarta: Penerbit Andi

Tsukamoto, H. 2006. Manga Matrix: Create Unique Characters Using the Japanese Matrix System, USA: Collins Design.
Internet:

http://www.andriewongso.com/articles/ details/5141/Inilah-3-Game-Klasik-

Sepanjang-Masa

https://moba.garena.co.id/main/news/sh ow/320

https://play.google.com/store/apps/detai ls?id=com.garena.game.kgid

https://venturebeat.com/2014/09/01/thehistory-of-mobas-from-mod-tosensation/ 